Portland State University

PDXScholar

\title{
The Breeding Biology of the Northern Pygmy Owl: Do the Smallest of the Small Have an Advantage?
}

John F. Deshler

Portland Water Bureau

Michael T. Murphy

Portland State University, murphym@pdx.edu

Follow this and additional works at: https://pdxscholar.library.pdx.edu/bio_fac

Part of the Biology Commons, Ornithology Commons, and the Population Biology Commons Let us know how access to this document benefits you.

Citation Details

Deshler, J. F. and Murphy, M. T. (2012). The Breeding Biology of the Northern Pygmy Owl: Do the Smallest of the Small Have an Advantage?. The Condor. 114(2): 314-322.

This Article is brought to you for free and open access. It has been accepted for inclusion in Biology Faculty Publications and Presentations by an authorized administrator of PDXScholar. Please contact us if we can make this document more accessible: pdxscholar@pdx.edu. 


\title{
THE BREEDING BIOLOGY OF THE NORTHERN PYGMY-OWL: DO THE SMALLEST OF THE SMALL HAVE AN ADVANTAGE?
}

\author{
John F. Deshler ${ }^{1,2,3}$ And Michael T. Murphy ${ }^{1}$ \\ ${ }^{1}$ Department of Biology, Portland State University, 1719 SW $10^{\text {th }}$ Ave. Portland, OR 97201 \\ ${ }^{2}$ Portland Parks \& Recreation, 1120 SW $5^{\text {th }}$ Ave \#1302, Portland, OR 97204
}

\begin{abstract}
We explored the breeding biology of the Northern Pygmy-Owl (Glaucidium gnoma) from 2007 to 2009 in a forested reserve in Portland, Oregon. Large body size is often assumed to give animals reproductive advantages, and we tested whether body size affected timing of breeding and examined variation in diet, breeding date, clutch size, and reproductive success to explore whether the presumed benefits of large body size are evident in this species. The average size of 13 clutches was 5.8, and nest success was high (92\%); 22 successful nests fledged an average of 5.2 young. Dates of first laying varied over an 18- or 19-day period in each year and averaged 3 weeks earlier in 2008 than in 2009. Early breeders laid larger clutches. After the effect of breeding site was controlled for, small rather than large female pygmy-owls bred earliest. The same pattern of small size was evident in all years. Diet varied by year in regard to whether mammals (2008) or birds (2007 and 2009) were the dominant prey taken, and the owls bred earlier in 2008 occurred when mammals dominated their diet. Although small females tended to breed earlier in all years, it was only in 2009 when pairs bred very late and birds dominated their diet that small females also laid larger clutches and fledged more young. These data suggest that the merits of small or large body size may vary with stages of the breeding cycle and ecological conditions.
\end{abstract}

Key words: $\quad$ body size, breeding biology, Glaucidium gnoma, pygmy-owl, timing of breeding.

Biología Reproductiva de Glaucidium gnoma: ¿Tiene lo Más Pequeño de lo Pequeño una Ventaja?

Resumen. Exploramos la biología reproductiva de Glaucidium gnoma desde 2007 hasta 2009 en una reserva forestada en Portland, Oregón. Usualmente se asume que el tamaño de cuerpo grande confiere a los animales ventajas reproductivas. Nosotros evaluamos si el tamaño de cuerpo afectó el periodo reproductivo y examinamos variaciones en la dieta, fecha reproductiva, tamaño de la nidada y éxito reproductivo para explorar si los presuntos beneficios del tamaño de cuerpo grande son evidentes en esta especie. El tamaño promedio de 13 nidadas fue 5.8 y el éxito de anidamiento fue alto (92\%); 22 nidos exitosos empollaron un promedio de 5.2 jóvenes. En todos los años, las fechas de puesta variaron a lo largo de un período de 19 días y comenzaron tres semanas antes en 2008 que en 2009. Los individuos que anidaron más temprano pusieron nidadas más grandes. Luego de controlar el efecto del sitio de anidación, en general las hembras más pequeñas de G. gnoma anidaron más temprano. El mismo patrón de tamaño pequeño fue observado en todos los años. La dieta varió por año según si los mamíferos (2008) o las aves (2007 y 2009) fueron las presas dominantes tomadas y las lechuzas anidaron más temprano en 2008 cuando los mamíferos dominaron sus dietas. Aunque las hembras pequeñas tendieron a anidar más temprano en todos los años, fue sólo en 2009, cuando las parejas anidaron muy tarde y las aves dominaron sus dietas, que las hembras pequeñas también pusieron nidadas más grandes y emplumaron más jóvenes. Estos datos sugieren que los méritos de un tamaño pequeño o grande de cuerpo pueden variar con las etapas del ciclo reproductivo y las condiciones ecológicas.

\section{INTRODUCTION}

The timing of birds' breeding and reproductive output are often highly dependent on food supply (reviewed in Martin 1987, Verhulst and Nilsson 2008). Food may have a particularly important influence on the reproductive biology of predators of vertebrates. Among the Strigiformes (Korpimäki 1987, Gehlbach 1994, Korpimäki and Weihn 1998, Seamans et al. 2002, LaHaye et al. 2004) and Falconiformes (Stinson 1980, Swenson 1986, Steenhof et al. 1997) the date of laying and reproductive output often vary directly with food abundance that is driven by climatic cycles or annual variation in weather.

Within a season, the reproductive output of early breeders is often greater than that of late breeders (von Haartman 1967, Källender 1974, Lundberg 1981, Murphy 1986, Verhulst et al. 1995, reviewed in Drent 2006), so traits that favor early breeding are at a selective advantage. However, mistiming of breeding by starting too early can lead to near total reproductive failure (Seamans et al. 2002, Lint 2005). Hence strong selection for early breeding is presumably constrained by either the immediate costs of a premature start or by females'

Manuscript received 21 July 2010; accepted 23 November 2011.

${ }^{3}$ E-mail: johndeshler@yahoo.com

The Condor, Vol. 114, Number 2, pages 314-322. ISSN 0010-5422, electronic ISSN 1938-5422. @ 2012 by The Cooper Ornithological Society. All rights reserved. Please direct all requests for permission to photocopy or reproduce article content through the University of California Press's Rights and Permissions website, http://www.ucpressjournals.com/ reprintInfo.asp. DOI: 10.1525/cond.2012.100140 
inability to acquire resources sufficient to bring them into breeding condition. The ability to bring a female into laying condition is likely to vary with territory quality and access to abundant food, although individual variation may also be an important factor. Larger body size and greater body mass are widely assumed to indicate high quality, presumably either because larger individuals store more of the resources used to fuel reproduction (Verhulst et al. 1995, Verhulst and Nilsson 2008) or large size yields an advantage in competition for high-quality breeding sites (Langston et al. 1990). Regardless, large size is commonly viewed as a predictor of greater fitness (Weimerskirch 1992, Wendeln 1997). However, theoretical arguments (Downhower 1984, Blanckenhorn 2000) and some empirical studies (Murphy 1986, Barbraud et al. 2000, Massemin et al. 2000, Rotella et al. 2003) suggest that small body size may sometimes yield reproductive advantages. Smaller individuals may be able to breed earlier and/or lay a larger clutch because smaller individuals can shunt more of their daily food intake into reproduction because they require less energy to meet their daily energy needs. Additionally, the merits of being small or large may vary from year to year, and smaller individuals can realize an advantage in years of low food abundance (Massemin et al. 2000). Indeed, the energetic benefits of having a small mate in years of low food abundance may be the foundation of reversed sexual size dimorphism in owls (Hakkarainen and Korpimäki1991), and the energetic benefits of being small may outweigh the supposed benefits of being large, such as improved nest defense (Korpimäki 1986, Hakkarainen and Korpimäki 1993). For species in which males provide food to females throughout the pre-laying and nesting periods, small females may have a reproductive advantage because it may be easier for males to meet the pair's energy needs. This is most likely true of species that are relatively small and whose reproduction is supported mostly through daily food intake rather than by fat stores (Meijer et al. 1989).

The Northern Pygmy-Owl (Glaucidium gnoma) is a small, diurnal, cavity-nesting owl that inhabits forests of western North America. Although widely distributed, the pygmyowl is an inconspicuous breeder, and except for the eight nests Giese and Forsman (2003) located in Washington from 1996 to 1999 , knowledge of its breeding biology consists of only a smattering of temporally and geographically disconnected accounts of nests (compiled in Holt and Peterson 2000). In an attempt to provide a comprehensive account of the life history of the pygmy-owl, we documented the reproductive ecology of a population over 3 years. Our two primary objectives were to (1) document the basic natural history of this understudied owl, and (2) describe annual variation in the timing of breeding and reproductive output to explore whether the presumed benefits of large body size are evident in this species. We therefore tested whether body size affected nest initiation by year and whether the timing of breeding, clutch size, and fledgling production varied consistently by year with body size, diet, and body mass.

\section{METHODS}

\section{STUDY SITE AND POPULATION CENSUS}

Our study took place in Forest Park, a 2145-ha urban park located on the northwest boundary of the city of Portland, Oregon. The roughly rectangular park, $13 \mathrm{~km}$ long and $1.6 \mathrm{~km}$ wide, is a protected, mature forest in which bigleaf maple (Acer macrophyllum), red alder (Alnus rubra), Douglas-fir (Pseudotsuga menziesii), western red cedar (Thuja plicata) and western hemlock (Tsuga heterophylla) are the dominant canopy trees. The understory of shrubs, ferns, and forbs is well developed and dominated by native plants such as sword fern (Polystichum munitum), Oregon grape (Mahonia aquifolium), salal (Gaultheria shallon), red elderberry (Sambucus racemosa), vine maple (Acer circinatum) and Indian plum (Oemleria cerasiformis).

To census the park systematically and completely, we superimposed a grid of 36-ha square blocks on a map of the park, laid out survey transects, and traversed each grid block three times each year. During surveys, we broadcast and vocally mimicked male pygmy-owls' calls; we are confident we located all adult males. We found nests by detecting sexspecific contact calls, which were often made in the vicinity of the nest.

\section{NEST MONITORING}

We recorded nest locations with a hand-held GPS unit (GPSmap 60CSx, Garmin, Inc., Olathe, KS). Nests often exceeded $6 \mathrm{~m}$ in height, and we used a custom-built, pole-mounted, wireless nest-cavity viewer (Huebner and Hurteau 2007) to check nest contents. We checked nests irregularly because of our desire to minimize disturbance over the lengthy incubation and nestling periods, but checks were never more than 9 days apart and were more frequent at hatching and fledging. Only one of 12 nests with information on both clutch size and number of fledged young showed a difference (five young fledged from a clutch of 6 eggs), so to estimate the clutch size of nests discovered after hatching, we used the number of nestlings at accessible nests ( $\leq 9 \mathrm{~m}$ high, $n=9$ ), and number of recently fledged young at inaccessible ones ( $>9 \mathrm{~m}$ high, $n=$ 6 ). We determined the date of laying of the first egg by direct observation or estimated it by backdating from hatching. For nests that were inaccessible or located late in the season, we estimated the date of laying from the date of fledging by the equation laying date $=$ fledging date $-[57+(1.5$ (clutch size 1)], where 1.5 is the estimated number of days between laying of successive eggs (Proudfoot 1996) and 57 is the combined length of the incubation and nestling periods. We considered a nest successful if $\geq 1$ owlet fledged and productivity as the number of fledged young per nest. Because the daily mortality 
rate was extremely low, we did not use the Mayfield method to estimate survival. Some nests were unreachable or difficult to view even when the nest camera could be inserted, so we also located broods within one to two days after fledging to determine productivity. Pseudoreplication was not a significant concern for our estimate of clutch size because (1) turnover in the population was high, territories were usually occupied by different females in successive years, and (2) females that did use the same territory in successive years seldom used the same cavity, so the clutch size of individual females was unlikely to reflect limitation by cavity volume.

We recorded prey type from direct observations of prey eaten by adults and young rather than from analyses of prey from pellets or simply prey delivered to young at the nest. Most observations were of males delivering prey to females, and the females fed upon this prey during the courtship, laying, incubation, and nestling periods. We also observed adult and juvenile owls capturing prey for their own consumption, and adults delivered prey to young both in and out of the nest. We categorized prey as avian, mammalian, or insect.

\section{CAPTURE AND BANDING}

To capture adult and juvenile pygmy-owls, we used a mist net with a live mouse as a lure or by placing a mist net near the front of the nest cavity. We plucked recently fledged owlets from branches or off the ground or captured them with a polemounted net. We affixed a U.S. Geological Sruvey band to the right leg of each captured bird and measured its body mass, wing chord, culmen, tarsus, and tail lengths. We sexed adults by the presence (female) or absence (male) of a brood patch. Although we recaptured some individuals in more than one year, pseudoreplication of body size and nest-initiation date were not a significant concern because, as noted above, rates of turnover of adults within pairs was high, such that in no case were we able to confirm that both adults of a mated pair used the same site in consecutive years. Additionally, we regularly detected replacement of mates, particularly of females, in successive years. At a given site, the cavity used was often far from the previous year's cavity (Deshler 2010), further reducing concerns that data were pseudoreplicated.

\section{STATISTICAL ANALYSES}

Although body mass is generally a good estimator of size, the body mass of female pygmy-owls is likely to vary substantially with time since her most recent meal and with stage of the reproductive cycle. Inferring that body mass was not useful for comparisons of size among females, we instead ran a principal component analysis (PCA) to compute a bodysize index from tarsus and culmen lengths. This allowed us to test for relationships between reproduction and structural body size. Loadings for tarsus and culmen length on the first principal component were both 0.701 ; high scores on factor 1 thus indicated large size. Among females, wing chord and tail length were not correlated with each other or any other measure of body size $(-0.24 \leq r \leq 0.19$ and $P \geq 0.35$ for both measures and all comparisons), so we did not include them in the index.

To estimate the date of laying each year we used first clutches only, and for the analysis of clutch size and laying date we excluded an incomplete clutch that was depredated. We also created a variable "clutch class" to distinguish between nests where we were able to actually count eggs (clutch class 1) and nests for which we estimated clutch size from the number of young (clutch class 0 ).

We used analysis of variance (ANOVA), general linear models (GLM), and two-sample $t$-tests to compare adult body mass, timing of breeding, clutch size, and number of fledged young among and within years. To test for change in adult body mass over the course of the nest cycle we standardized capture dates by creating a date ("nest age") that corresponded to the time elapsed in days between the day the first egg was laid (day 1) and the date of capture of each adult. Mean date of laying differed by year (see below), so we standardized it for some analyses by subtracting the Julian date of the day before the earliest egg was laid each year from the start date of all clutches in that year. Thus day 1 was the first date of laying by any female in a given year. We also compared discrete groupings of early- (standardized laying date $\leq$ day 7 ; range 1-18.5 days) and late-breeding females (standardized laying date $>$ day 7). GLM analysis of laying date included site (i.e., territory) as a random factor and the body size index of the female as a covariate. We did similar GLM analyses of clutch size and number of fledged young, except that we included laying date as a covariate and clutch class as a fixed factor in the GLM of clutch size to account for possible loss of eggs before hatching from nests in which clutch size was not directly observed.

To examine synchrony of breeding, we calculated coefficients of variation (CV), and used 1.0 as the threshold for high variation within any factor, considering variation high if the standard deviation was greater than the mean (Hendricks and Robey 1936). We used Pearson's correlation coefficients and simple linear regressions to explore relationships between metrics of breeding and dietary composition. We obtained daily mean temperature and precipitation from the closest available $(9.8 \mathrm{~km})$ weather station, at the Portland International Airport (www.weather-warehouse.com), and we summarized these data into six 21-day periods beginning 11 December of the previous year and ending on 15 April. These dates encompassed the period of approximately 4 months prior to and including the start of the pygmy-owl's breeding season. Because precipitation data were not normally distributed, we $\log _{10}$-transformed precipitation after first adding 0.001 prior to transformation and then adding 3.0 to restore transformed values of -3.0 (i.e., no precipitation) to a value of zero, thereby achieving normality. We examined annual variation in the six weather periods with analysis of variance 
(ANOVA) and Tukey's HSD tests and used linear regression to analyze the annual date of laying in relation to mean precipitation and temperature for each of those periods.

Because our sample sizes were relatively small, we included the maximum possible number of cases for each type of analysis rather than selecting a fixed number of cases for all analyses. For example, for an analysis of the relationship between body size and clutch size, we used the 22 cases for which we had information on complete clutches and female size. However, for our analysis of the relationship between body size and fledged young, we necessarily omitted the two, rare, failed nests and the one case for which we did not obtain the female's body size, and so used only 19 cases. The results of some analyses closely approached, but did not reach, the usual criterion for statistical significance $(P \leq 0.05)$. Nevertheless, in a few cases we report results with $0.05<P<0.075$ as trends of potential biological significance because (1) our samples, though relatively small, are among the largest for describing the ecology of this species and (2) the standard cutoff for significance is arbitrary (Johnson 1999), We report means and standard error $(\bar{x} \pm \mathrm{SE})$ unless otherwise indicated.

\section{RESULTS}

\section{POPULATION SIZE, BANDING, AND}

\section{RECAPTURE RATES}

We found the nests of 5 of 12 territory holding males in 2007, all 10 territorial males in 2008, and 8 of 9 males in 2009. In total we found 24 nests (23 initial nests and one replacement nest) over the 3 years. Pygmy-Owls frequently nested at the same sites in successive years ( $n=12$ of 15 possible instances) but reused nest cavities only occasionally $(n=2)$.

We banded 17 female, 8 male, and 26 hatch-year pygmyowls at 11 sites. During the first 2 years, we captured and banded 13 of the 14 breeding females (93\%). Two of the 11 females captured in 2008 had been captured in 2007. We confirmed that two of the four females banded in 2007 had died by May 2008. In 2009, four of the six females captured on territories occupied in the prior year had not been previously banded. Recaptured banded owls (4 females, 1 male) were on their previous year's territory. No previously banded hatchyear birds were recaptured as breeders.

\section{LAYING, WEATHER, CLUTCH SIZE, NEST SUCCESS, AND PRODUCTIVITY}

Egg laying began significantly earlier in 2008 than in both 2007 and $2009\left(F_{2,22}=34.1, P<0.01\right.$; Table 1$)$. Within a year, breeding appeared to be fairly synchronous, as the dates of laying ranged over only about 19 days within any year $(\mathrm{CV}<0.07$ in all years). Annual variation in mean date of laying showed no relationship with mean precipitation and temperature for any of the 21-day weather periods $(P=0.08$ for mean temperature from 26 March to 15 April; $P>0.12$ for mean temperature and precipitation for all other periods). However, some obvious trends in the weather were consistent with trends in laying date: (1) the delayed 2009 breeding season was preceded by a colder mid-to-late December than were the 2007 and 2008 seasons $\left(F_{2,60}=6.51, P<0.01\right.$; Tukey's HSD), and (2) the early 2008 breeding season was preceded by the period from 12 February to 4 March being warmer than in $2009\left(F_{2,60}=3.11, P<0.05\right.$; Tukey's $)$, and 2008 was dryer than $2007\left(F_{2,60}=4.47, P=0.02\right.$; Tukey's HSD) during the same March period.

Of the 13 observed clutches, 5 had 6 eggs, 4 had 5 eggs, and 3 had 7 eggs; only 1 had 4 eggs. Clutches observed prior to hatching were larger than those estimated from the number of observed young (5.8 \pm 0.3 vs. $4.8 \pm 0.3, t_{17}=-2.40, P=0.03$ ), and the size of observed clutches averaged larger in 2008 than $2009\left(6.4 \pm 0.2\right.$ vs. $\left.5.5 \pm 0.3, t_{9}=2.14, P=0.062\right)$. The difference between the years was diminished when we included nests for which clutch size was estimated from the number of young observed $\left(F_{2,22}=2.64, P=0.10\right)$. Clutch size declined with date of laying $\left(F_{1,6}=8.378, P=0.03, n=23\right)$, was independent of site $\left(F_{10,2}=0.884, P=0.64, n=23\right)$, and was larger in nests in which clutch size was directly observed $\left(F_{1,5}=\right.$ $9.425, P=0.03, n=23)$. There was no interaction between site and whether or not clutch size was directly observed $\left(F_{4,6}=\right.$ $0.673, P=0.49, n=23)$. Multiple regression analysis of clutch size against laying date and clutch class accounted for $44 \%$ of the variation and suggested that clutch size declined seasonally at a rate of $0.04 \mathrm{eggs} \mathrm{day}^{-1}(\mathrm{SE}=0.016, P=0.02)$.

At one easily accessible nest, three eggs required 29 days to hatch, and our best estimate was that incubation required 30 days ( $n=8$ observed nests; Table 1$)$. The nestling period averaged 27 days (Table 1), and, on average, broods left the nest over a period of $2.3 \pm 0.2$ days $(n=16$ nests, range $1.5-5$ days). Young fledged from 22 of 24 (92\%) initial nests, and three fledglings from a replacement nest were found late in one season. The average successful nest fledged five young (Table 1). Number of fledged young was independent of site (GLM: $F_{10,5}=0.853, P=0.61, n=18$ ).

\section{FEMALE BODY SIZE AND TIMING OF BREEDING}

Our GLM analysis of timing of breeding showed that early laying was associated with small body size of females $\left(F_{1,8}=7.130\right.$, $P=0.03$; Fig. 1) and varied with site $\left(F_{10,8}=4.72, P=0.02, n=\right.$ 20 attempted nests). Small females consistently initiated laying during the first week of the season, and larger females initiated laying during the second week (Fig. 1). Site effects were related to the consistently late start by pairs breeding in territory FL12, at which laying began during the third week of each season, an effect that appeared unrelated to a specific female because different females occupied the site each year. A multiple regression of standardized laying date against body size $(b=1.88 \pm 0.538, P=0.003)$ and a dummy variable that distinguished between FL12 and all other nests $(b=11.2 \pm 1.86$, 
TABLE 1. Productivity and chronology (mean \pm SE) of 22 successful nests of the Northern Pygmy-Owl in Forest Park, Portland, Oregon, 2007-2009.

\begin{tabular}{|c|c|c|c|c|c|c|c|c|}
\hline Year & $n$ & $\begin{array}{l}\text { Min. } \\
\text { clutch }\end{array}$ & $\begin{array}{c}\text { Min. } \\
\text { fledged }\end{array}$ & $\begin{array}{c}\text { Laying } \\
\text { start }\end{array}$ & $\begin{array}{c}\text { Hatching } \\
\text { start }\end{array}$ & $\begin{array}{c}\text { Fledging } \\
\text { start }\end{array}$ & $\begin{array}{c}\text { Incubation } \\
\text { (days) }\end{array}$ & $\begin{array}{l}\text { Nestling } \\
\text { (days) }\end{array}$ \\
\hline 2007 & 5 & $4.6 \pm 0.5$ & $4.6 \pm 0.5$ & $21 \mathrm{Apr} \pm 3.1$ & 27 May \pm 3.0 & 22 Jun \pm 3.0 & $33.0 \pm 0.0$ & $26.5 \pm 1.5$ \\
\hline 2008 & 9 & $5.7 \pm 0.3$ & $5.6 \pm 0.3$ & $4 \mathrm{Apr} \pm 1.4$ & $10 \mathrm{May} \pm 1.7$ & 6 Jun \pm 1.6 & $29.7 \pm 0.7$ & $27.0 \pm 1.0$ \\
\hline 2009 & 8 & $5.1 \pm 0.4$ & $5.1 \pm 0.4$ & $25 \mathrm{Apr} \pm 1.9$ & 30 May \pm 1.7 & 27 Jun \pm 1.7 & $29.5 \pm 0.5$ & $27.3 \pm 0.6$ \\
\hline All & 22 & $5.2 \pm 0.2$ & $5.2 \pm 0.2$ & $16 \mathrm{Apr} \pm 2.3$ & $21 \mathrm{May} \pm 2.2$ & 17 Jun \pm 2.2 & $30.0 \pm 0.5$ & $27.0 \pm 0.5$ \\
\hline
\end{tabular}

$P<0.001)$ accounted for $73 \%$ of the variation in date of laying when all nests with information on both body size and laying date $(n=20)$ were included in the analysis $(P<0.01)$.

We further examined the association between female body size and timing of breeding, eliminating the females consistently breeding very late at site FL12 (Fig. 1), and comparing the average body size of early (laying date $\leq$ day 7 ) and late breeders (laying date $>$ day 7). For all years combined, females breeding early were smaller than those breeding late (Table 2). Direct comparison of tarsus and culmen lengths of early and later breeders showed that both traits were shorter in early breeders (Fig. 2). By year, females breeding early in $2008(n=5)$ appeared to be smaller $(-1.15 \pm 0.40)$ than late ones $\left(0.43 \pm 0.6, n=5 ; t_{8}=2.3, P=0.05\right)$. In 2009 early-breeding females $(-0.76 \pm 0.6, n=3)$ again appeared to be smaller than late ones $\left(1.06 \pm 0.4, n=4 ; t_{5}=2.74, P=\right.$ 0.04). The sample for 2007 was too small for analysis. When we included females from site FL12, early breeders were still smaller than late ones $\left(-0.87 \pm 0.3\right.$ vs. $0.81 \pm 0.3, t_{19}=3.86$, $P=0.001)$ for all three years combined.

\section{CLUTCH SIZE AND TIMING OF BREEDING}

For all years combined, the sizes of clutches of early $(n=10)$ and late females $(n=11)$ were similar $(5.7 \pm 0.3$ vs. $5.0 \pm 0.3$,

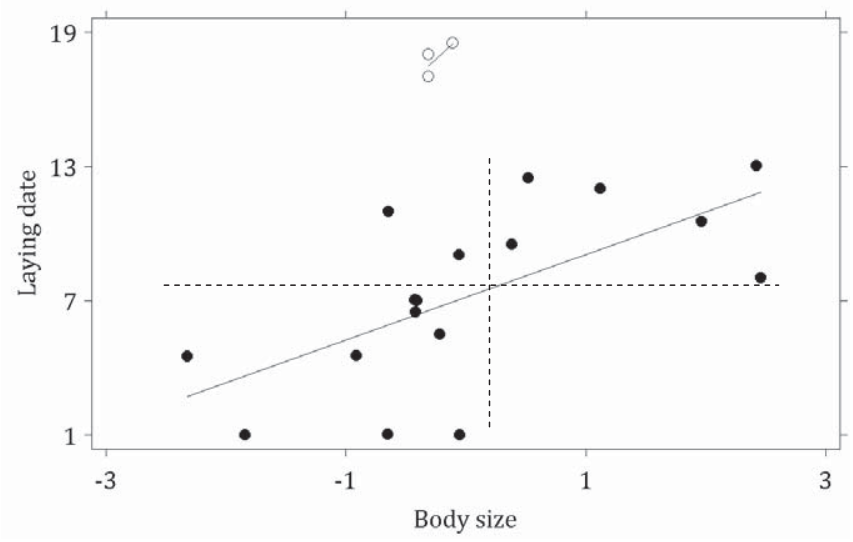

FIGURE 1. Standardized laying date $(1=$ start of laying in each year, $n$ $=20$ nests) plotted against body-size index for female Northern PygmyOwls in Forest Park, Portland, Oregon 2007 - 2009. The plot controls for the effect of territory FL12 (unfilled circles, $n=3$ nests), site of latest breeding in each of the three years. $\left.t_{19}=-1.56, P=0.14\right)$. In comparisons by year, in 2008 , the year of greater use of mammalian prey and overall earlier breeding, early breeders did not lay larger clutches than late ones $\left(6.0 \pm 0.3\right.$ vs. $5.6 \pm 0.5$ eggs, $\left.t_{8}=0.7, P=0.52\right)$, and they fledged no more young (5.6 \pm 0.5 vs. $4.4 \pm 1.1, t_{8}=-0.97, P=$ $0.36)$. However, in 2009 , a year of greater use of avian prey and overall later breeding, the smaller early-breeding females appeared to lay larger clutches ( $6.0 \pm 0.6$ vs. $4.5 \pm 0.3$ eggs, $t_{5}=$ $-2.54, P=0.052)$, and because all eggs hatched and all young fledged, they also tended to fledge more young ( $6.0 \pm 0.6 \mathrm{vs}$. $4.5 \pm 0.3, t_{5}=-2.54, P=0.052$ ).

\section{FLEDGED YOUNG AND TIMING OF BREEDING}

According to our GLM of the 19 successful nests at which we had information on the female's body size (two failed nests and one without data on the female's body size omitted), the number of fledged young was independent of body size $\left(F_{1,5}=0.297, P=0.61\right)$, date of laying $\left(F_{1,6}=0.694, P=0.44\right)$, and site $\left(F_{10,5}=0.853, P=0.61\right)$. However, the number of fledged young correlated negatively with the female's body size ( $n=19, r=-0.46, P=0.05)$, suggesting that smaller females nevertheless fledged more young. So we also explored the relationship between body size and number of fledged young inter-annually by differentiating between early (laying date $\leq$ day $7 ; n=9$ ) and late (laying date $>$ day $7 ; n=10$ ) breeding, finding that early females were smaller $(-0.77 \pm$ 0.26 vs. $\left.0.57 \pm 0.34, t_{17}=3.12, P=0.007\right)$ and tended to fledge more young ( $5.8 \pm 0.3$ vs. $\left.5.0 \pm 0.2, t_{17}=-2.05, P=0.064\right)$. Furthermore, when we considered all 22 successful nests including those without information on the female's body size, early females $(n=10)$ fledged more young $(5.7 \pm 0.3$ vs. $4.3 \pm$ $\left.0.5, t_{20}=-2.35, P=0.03\right)$ than late ones $(n=12)$.

\section{VARIATION IN BODY MASS AND DIET}

The body mass of adult females $(r=-0.45, P=0.06$, $\mathrm{df}=$ 17; Fig. 3) but not that of males ( $r=0.43, P=0.40, \mathrm{df}=5$ ) tended to decline over the nest cycle. In 2007 and 2009 females' body mass was similar $(75.3 \pm 2.5$ vs. $75.5 \pm 2.6 \mathrm{~g}$; combined $=75.4 \pm 1.7 \mathrm{~g}, n=10$ ), but in 2008 females appeared to be heavier $(80.8 \pm 2.9 \mathrm{~g}, n=9)$. To test for variation of body mass over the breeding cycle and by year, we combined data for 2007 and 2009 for comparison to 2008, then examined body mass in relation to nest age, using analysis of covariance with body size as a covariate. Females were heavier in 2008 
TABLE 2. Comparison of body metrics (mean $\pm \mathrm{SE}$ ) for females that bred within the first 7 days of the breeding season (i.e., early females) or later (i.e., late females) and between adult male $(n=8)$ and adult female $(n=17)$ Northern Pygmy-Owls captured in Forest Park, Portland, Oregon, 2007-2009.

\begin{tabular}{lcccccc}
\hline \hline Character & Early females & Late females & $t(P)$ & Females & Males & $t(P)$ \\
\hline Body size (PC1) & $-0.77 \pm 0.26$ & $1.12 \pm 0.42$ & $3.56(0.003)$ & $0.31 \pm 0.27$ & $-0.67 \pm 0.38$ & $2.11(0.05)$ \\
Culmen (mm) & $13.1 \pm 0.1$ & $13.7 \pm 0.2$ & $3.32(0.008)$ & $13.4 \pm 0.1$ & $12.9 \pm 0.2$ & $2.46(0.03)$ \\
Mass (g) & $75.0 \pm 1.3$ & $80.1 \pm 3.9$ & $1.37(0.19)$ & $76.8 \pm 1.6$ & $61.9 \pm 0.9$ & $6.29(<0.001)$ \\
Tarsus (mm) & $25.9 \pm 0.4$ & $27.6 \pm 0.4$ & $2.98(0.01)$ & $26.5 \pm 0.9$ & $25.9 \pm 0.4$ & $1.11(0.28)$ \\
Wing chord (mm) & $93.0 \pm 0.4$ & $92.8 \pm 0.2$ & $-0.30(0.77)$ & $93.1 \pm 0.3$ & $88.6 \pm 0.8$ & $6.21(<0.001)$ \\
\hline
\end{tabular}
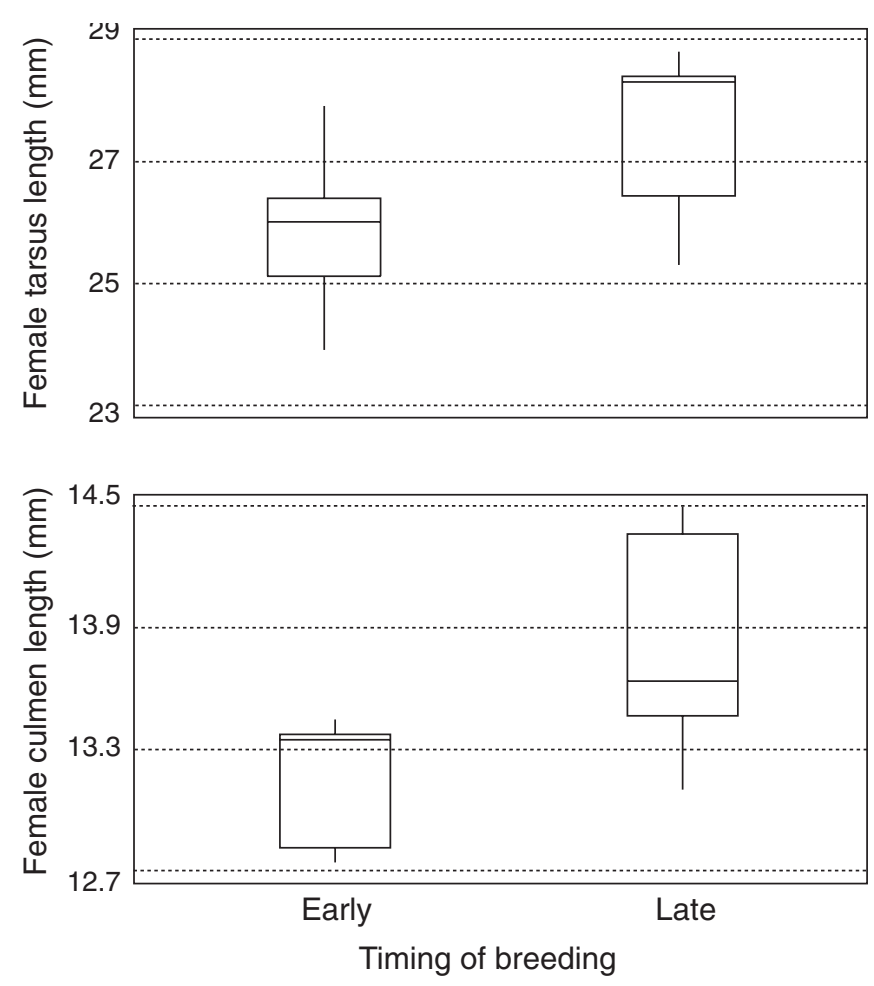

FIGURE 2. Box and whisker plots that compare tarsus and culmen lengths of early- and later-breeding female Northern Pygmy-Owls in Forest Park, Portland, Oregon, 2007-2009. Boxes enclose the middle $50 \%$ of observations, the horizontal line represents the median, and vertical lines encompass the range of observations.

$\left(F_{1,18}=4.61, P=0.05\right)$, and mass declined with nest age $\left(F_{1,18}=\right.$ $4.39, P=0.05)$. Additionally, females were structurally larger than males and averaged $24 \%$ heavier (Table 2 ). Body mass had no relationship to body size for either females $(r=0.01$, $P=0.96, \mathrm{df}=15)$ or males $(r=0.26, P=0.51, \mathrm{df}=7)$.

Data from the three years pooled, birds and mammals contributed roughly equally to the $\operatorname{diet}(52 \% \mathrm{vs} .48 \% ; n=125$ observed prey items). However, mammals formed a greater portion of the diet in $2008(69 \%, n=61)$ than in either 2007 $(39 \%, n=31)$ or $2009(15 \%, n=33$; Fisher's exact test; 2007 vs. 2008: $P=0.007$; 2008 vs. 2009 : $P<0.001$; Fig. 4). Birds constituted a larger portion of the diet in 2009 (82\%) than in 2007 (61\%; Fisher's exact test, $P=0.05)$. Because many species of potential avian prey were migrants that did not return before 15 April, we tested for both annual and seasonal variation in prey composition by logistic regression with prey designated as mammals (scored as 1) or birds (scored as 0 ; one butterfly omitted from the analysis). We found that mammals were eaten more often early in the breeding season (coefficient $[b]=-0.018, \mathrm{SE}=0.007, P=0.008)$ and more often in the first two years, especially in $2008(b=-0.596, \mathrm{SE}=0.264$, $P=0.02)$.

\section{DISCUSSION}

Pygmy-Owls in Forest Park invested heavily in reproduction during each breeding season and were highly successful in comparison to cavity-nesting raptors of similar size (Gehlbach 1994, Proudfoot 1996, Smallwood and Bird 2002). Clutches of 6 or 7 eggs were common, nestling survival was high, nest failures were rare, and offspring survival appeared to be high in the few weeks immediately following fledging. Indeed, throughout our study, pygmyowls bred very successfully.

Mammalian prey are critically important for many temperate-zone owl species (Forsman et al. 1984, Korpimäki and Hakkarainen 1991, Korpimäki 1992, Rohner et al. 1995, Rohner 1996), and the link between the abundance and availability of prey and reproduction has been well established for owls (Southern and Lowe 1968, Korpimäki 1986). Although we did not systematically measure the abundance of avian or mammalian prey, we recorded prey use continuously throughout each season, and from these data it appeared that mammalian prey were also particularly important for early breeding by pygmy-owls. In 2008, egg laying, which began well in advance of the arrival of many migrant birds, was significantly earlier than in the other years, and mammalian prey were taken more often than avian prey. If use reflects availability, the start 2 to 3 weeks earlier in 2008 than in the two other years may have been possible because of an abundant supply of mammalian food. In contrast, 2009 was a comparatively poor year for reproduction. In 2009, female pygmy-owls weighed less, egg laying was delayed, birds dominated the diet, and there was no seasonal shift from mammalian to avian prey as in 2008 (Deshler 2010). 


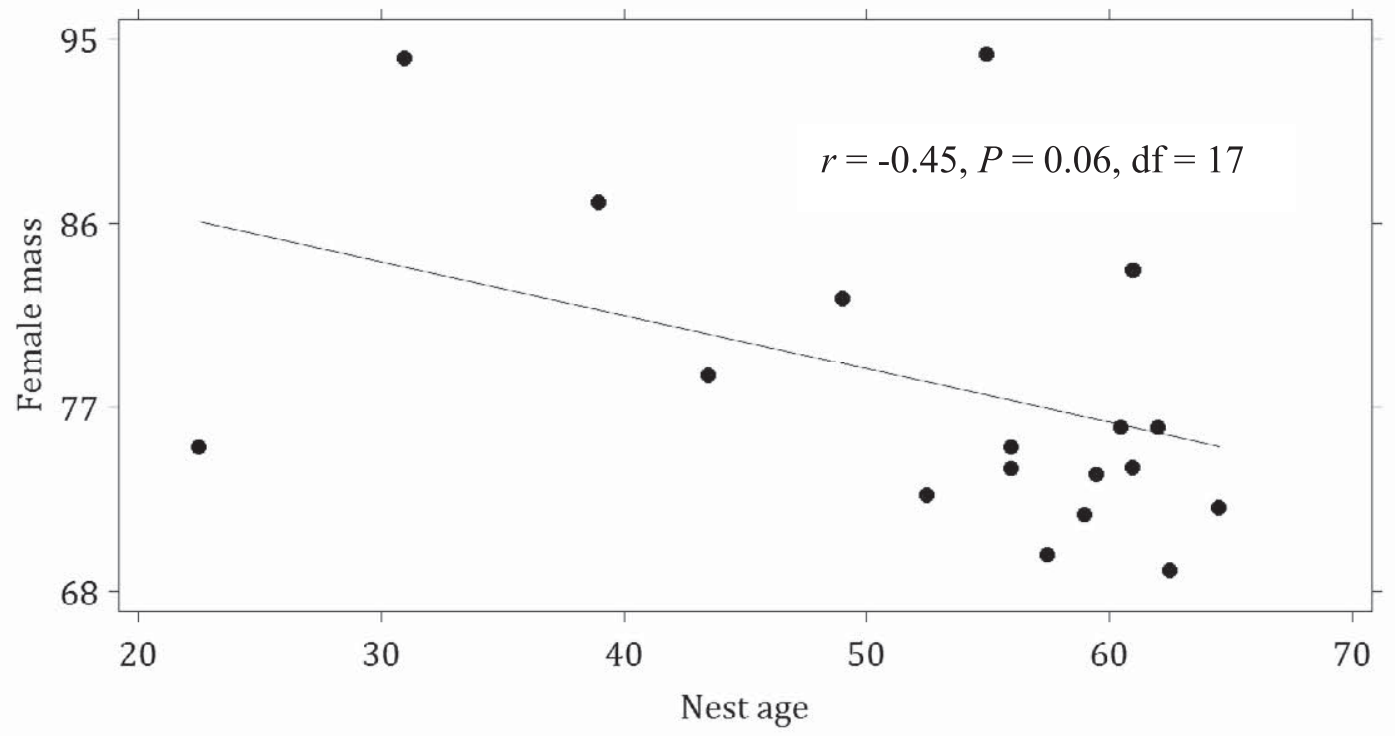

FIGURE 3. Mass of the female plotted against age of the nest for Northern Pygmy-Owls breeding in Forest Park, Portland, Oregon, $2007-2009$. Nest age was computed by subtracting the start of laying (Julian date) for a given female from its date of capture, such that $1=$ start of laying for each female.

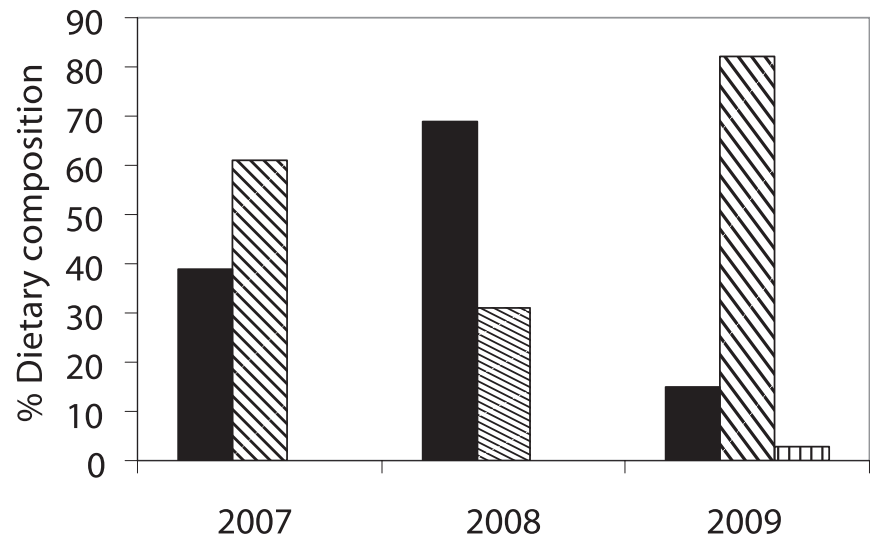

FIGURE 4. Percent dietary composition of prey, mostly delivered to the nest, for pygmy-owls on the Forest Park study area, Portland, OR 2007-2009. Prey were small mammals (black), birds (slanted lines) and insects (vertical lines).

We found that females' body mass varied with nest stage, and that fact, along with the unpredictability of a meal prior to a bird's capture and measurement, meant that body mass per se was not a reliable measure of overall size. Nonetheless, average body mass yields information on a population's condition (i.e., health) within a given year. The heavier body mass of females in 2008, the near complete reliance on mammalian prey in that year, and the success of the first documented attempt by a pygmy-owl to renest strongly suggest that 2008 was the best of the three years for this species, In contrast, 2009 was a late year in which females' body mass was low, birds dominated the diet, and both clutch size and fledgling production were below those of 2008 .

\section{EARLY BREEDING AND FEMALE BODY SIZE}

Among the pygmy-owls we studied, small females were the first to breed. Selection for early breeding is widely recognized as important because of its association with larger clutch size (Lack 1966, Rowe et al. 1994, Sheldon et al. 2003) but also with the increased probability of renesting after failure of an initial attempt and increased likelihood of recruitment of offspring (Shutler et al. 2006, Dolan et al. 2009). We collected no information on offspring recruitment, but the clutch size of pygmy-owls at Forest Park declined seasonally, suggesting that early breeding was advantageous. Although large body size is typically associated with reproductive advantages, including early breeding (Langston et al. 1990), we and others (Murphy 1986, Barbraud et al. 2000, Massenin et al. 2000) have shown that smaller females may have an advantage in being able to be the first individuals to initiate egg production. For females, the benefit of small body size may manifest itself in the ability to shunt more food resources to reproduction rather than to maintenance. For males, small size may lead to increased aerial agility that improves efficiency of hunting and territory defense (Korpimäki 1986, Massemin et al. 2000). But whether small or large size yields an advantage may depend on annual differences in environmental conditions. For instance, Massemin et al. (2000) showed that small female Eurasian Kestrels (Falco tinnunculus) were able to produce more young than were larger females, but only in seasons of low or declining prey abundance. Similarly, though with a smaller sample, our data indicate that at Forest Park small female pygmy-owls bred earlier each year but achieved a reproductive advantage over large females via increased clutch and fledgling production only in 2009, a relatively poor year. And, in parallel to the conclusions of Massemin et al. (2000), the abundance of early-season mammalian prey in 
2008 appeared to obviate the benefits for small females, so the absence of a difference in clutch size between early- and late-breeding pygmy-owls in that year should not have been unexpected. Thus, whether or not early breeding yields reproductive advantages for owls in general, and for smaller females in particular, may depend on the year and environmental conditions that are manifested in the abundance of mammalian prey. The apparent decline in mammalian prey in 2009 may have been caused by the harsh winter of 2008-2009, when precipitation was not unusually high but unusually cold temperatures left snow covering the ground at our site continuously for several weeks in mid-winter, an unusual occurrence in this region. Additional years of data on prey abundance, environmental conditions, and pygmy-owl reproduction are needed to fully test the hypothesis that small body size has reproductive advantages that are manifested only in years of low or declining mammalian prey abundance. But the initial years of our study suggest an intriguing interplay between evolutionary forces that sculpt the very physical structure of the Northern Pygmy-Owl.

\section{ACKNOWLEDGMENTS}

Eric Forsman provided valuable insights into pygmy-owl ecology and field methods, and his comments greatly improved several drafts of this manuscript. Eric also made available the raw data from two previous studies of the pygmy-owls. The Mazamas provided financial support during 2008. A group of volunteers worked hard to find pygmy-owl nests during 2008: Glen Mejia, Ian Matthews, Jeff Schwilk, Adam Elzinga, Lisa Ripps, Shawn Schmelzer, Mark Fitzsimmons, and Dawn Handy. A big thanks goes to the Portland Parks and Recreation Department for allowing unfettered research access to Forest Park. We also thank the Forest Park Conservancy crews who maintained trails and removed downed trees and thereby eased the exhausting burden of traversing steep, heavily vegetated terrain. The Portland Audubon Society helped with volunteer recruitment, allowed access to its wildlife sanctuary, and contacted JFD about pygmy-owls brought to its wildlife-care facility, leading to interesting insights on parental care after mate loss. We also thank two anonymous reviewers for their comments.

\section{LITERATURE CITED}

Barbraud, C., H. Lormée, And A. LeNevé. 2000. Body size and determinants of laying date in the Snow Petrel Pagodroma nivea. Journal of Avian Biology 31:295-302.

BLANCKENHORN, W. U. 2000. The evolution of body size: what keeps organisms small? Quarterly Review of Biology 75:385-407.

DeshLER, J. F. 2010. Nest-site habitat selection and breeding biology of the Northern Pygmy-Owl in northwestern Oregon. M.Sc. thesis, Portland State University, Portland, OR.

Dolan, A. C., M. T. Murphy, L. J. Redmond, and D. Duffield. 2009. Maternal characters and the production and recruitment of sons in the Eastern Kingbird (Tyrannus tyrannus). Behavioral Ecology and Sociobiology 63:1527-1537.

Downhower, J. F. 1976. Darwin's finches and the evolution of sexual dimorphism in body size. Nature 263:558-563.

DRENT, R. H. 2006. The timing of birds' breeding seasons: the Perrins hypothesis revisited especially for migrants. Ardea 94:305-322.

Forsman, E. D., E. C. Meslow, And H. M. Wight. 1984. Distribution and biology of the Spotted Owl in Oregon. Wildlife Monographs 87:3-64.
Gehlbach, F. R. 1994. The Eastern Screech-Owl: life history, ecology, and behavior in suburbia and the countryside. Texas A\&M University Press, College Station, TX.

Giese, A. R., And E. D. Forsman. 2003. Breeding season habitat use and ecology of male Northern Pygmy-Owls. Journal of Raptor Research 37:117-124.

HAKKARAINEN, H., AND E. KoRPIMÄKI. 1991. Reversed sexual-size dimorphism in Tengmalm's Owl: is small male size adaptive? Oikos 61:337-346.

HakKarainen, H., AND E. KorpimäKI. 1993. The effect of female body-size on clutch volume of Tengmalm's Owl Aegolius funereus in varying food conditions. Ornis Fennica 4:189-195.

HENDRICKS, W. A., AND K. W. RoBEY. 1936. The sampling distribution of the coefficient of variation. Annals of Mathematical Statistics 7:129-132.

Holt, D. W., And J. L. Petersen. 2000. Northern Pygmy-Owl (Glaucidium gnoma), no. 494. In A. Poole and F. Gill [EDS.], The birds of North America. Birds of North America, Inc., Philadelphia.

Huebner, D. P., And S. R. Hurteau. 2007. An economical wireless cavity-nest viewer. Journal of Field Ornithology 78:87-92.

JoHnson, D. H. 1999. The insignificance of statistical significance testing. Journal of Wildlife Management 63:763-772.

KÄLLENDER, H. 1974. The advancement of laying in the Great Tit by the provision of food. Ibis 116:365-376.

KoRPIMÄKI, E. 1986. Reversed size dimorphism in birds of prey, especially in Tengmalm's Owl Aegolius funereus: a test of the starvation hypothesis. Ornis Scandinavica 17:326-332.

KoRPIMÄKI, E. 1987. Timing of breeding of Tengmalm's Owl Aegolius funereus in relation to vole dynamics in western Finland. Ibis 129:58-68.

KORPIMÄKI, E. 1992. Fluctuating food abundance determines the lifetime reproductive success of male Tengmalm's Owls. Animal Ecology 61:103-111.

KorPIMÄKI, E., AND H. HAKKARAINEN. 1991. Fluctuating food supply affects the clutch size of Tengmalm's Owl independent of laying date. Oecologia 85:543-552.

KORPIMÄKI, E., AND J. WIEHN. 1998. Clutch size of kestrels: seasonal decline and experimental evidence for food limitation under fluctuating food conditions. Oikos 83:259-272.

LACK, D. 1966. Population studies of birds. Clarendon Press, Oxford, England.

LaHaye, W. S., G. S. Zimmerman, and R. J. GutiéRrez. 2004. Temporal variation in the vital rates of an insular population of Spotted Owls (Strix occidentalis occidentalis): contrasting effects of weather. Auk 121:1056-1069.

Langston, N. E., S. Freeman, S. Rohwer, And D. Gori. 1990. The evolution of female body size in Red-winged Blackbirds: the effects of timing of breeding, social competition, and reproductive energetics. Evolution 44:1764-1779.

LiNT, J. 2005. Northwest forest plan - the first 10 years (1994-2003): status and trends of Northern Spotted Owl populations and habitat. General Technical Report PNW-GTR-648. U.S. Department of Agriculture, Forest Service, Pacific Northwest Research Station, Portland, OR.

LundBerg, A. 1981. Population ecology of the Ural Owl (Strix uralensis) in central Sweden. Ornis Scandinavica 12:111-119.

Massemin, S., KorpimÄKI, E., AND Wiehn, J. 2000. Reversed sexual size dimorphism in raptors: evaluation of the hypotheses in kestrels breeding in a temporally changing environment. Oecologia 124:26-32.

MARTIN, T. E. 1987. Food as a limit on breeding birds: a life history perspective. Annual Review of Ecology and Systematics 18:453-487.

MeiJer, T., D. Masman, And S. DaAn. 1989. Energetics of reproduction in female kestrels. Auk 106:549-559. 
Murphy, M. T. 1986. Body size and condition, timing of breeding, and aspects of egg production in Eastern Kingbirds. Auk 103:465-476.

Proudfoot, G. A. 1996. Natural history of the Cactus Ferruginous Pygmy-Owl. M. Sc. thesis, Texas A\&M University, Kingsville, TX.

Rohner, C. J., N. M. Smith, And J. Stroman. 1995. Northern HawkOwls in the nearctic boreal forest: prey selection and population consequences of multiple prey cycles. Condor 97:208-220.

RoHner, C. J. 1996. The numerical response of Great Horned Owls to the snowshoe hare cycle: consequences of non-territorial floaters on demography. Journal of Animal Ecology 65:359-370.

Rotella, J. J., R. G. Clark, and A. D. Afton. 2003. Survival of female Lesser Scaup: effects of body size, age, and reproductive effort. Condor 105:336-347.

Rowe, L., D. Ludwig, AND D. Schluter. 1994. Time, condition, and the seasonal decline of avian clutch size. American Naturalist 143:698-722.

Seamans, M. E., R. J. Gutiérrez, And C. A. May. 2002. Mexican Spotted Owl (Strix occidentalis) population dynamics: influence of climatic variation on survival and reproduction. Auk 119: 321-334.

Sheldon, B. C., L. E. B. Kruuk, And J. Merilë. .2003. Natural selection and inheritance of breeding time and clutch size in the Collared Flycatcher. Evolution 57:406-420.

Shutler, D., R. G. Clark, C. Fehr, and A. W. Diamond. 2006. Time and recruitment costs as currencies in manipulation studies on the costs of reproduction. Ecology 87:2938-2946.

Smallwood, J. A., AND D. M. BirD. 2002. American Kestrel (Falco sparverius), no. 602. In A. Poole and F. Gill [EDS.],
The birds of North America. Birds of North America, Inc., Philadelphia.

Southern, H. N., AND Lowe, V. P. W. 1968. The pattern of distribution of prey and predation in Tawny Owl territories. Journal of Animal Ecology 37:75-97.

Steenhof, K., M. N. Kochert, AND T. L. McDonald. 1997. Interactive effects of prey and weather on Golden Eagle reproduction. Journal of Animal Ecology 66:350-362.

Stinson, C. H. 1980. Weather-dependent foraging success and sibling aggression in Red-tailed Hawks in central Washington. Condor 82:76-80.

Swenson, J. E., K. L. Alt, And R. L. Eng. 1986. Ecology of Bald Eagles in the greater Yellowstone ecosystem. Wildlife Monographs 95:3-46.

Verhulst, S., J. H. van Balen, And J. M. Tinbergen. 1995. Seasonal decline in reproductive success of the Great Tit: variation in time or quality? Ecology 76:2392-2403.

Verhulst, S., AND J. A. NiLsSON. 2008. The timing of birds' breeding seasons: a review of experiments that manipulated timing of breeding. Philosophical Transactions of the Royal Society B 363:399-410.

Von HaArtman, L. 1967. Clutch-size in the Pied Flycatcher. Proceedings of the International Ornithological Congress 14:155-164.

Weimerskirch, H. 1992. Reproductive effort in long-lived birds: age-specific patterns of condition, reproduction and survival in the Wandering Albatross. Oikos 64:464-473.

Wendeln, H. 1997. Body mass of female Common Terns (Sterna hirundo) during courtship: relationships to male quality. Colonial Waterbirds 20:235-243. 